\title{
Semisolid slurry of 7A04 aluminum alloy prepared by electromagnetic stirring and $\mathrm{Sc}, \mathrm{Zr}$ additions
}

\author{
*Jun-wen Zhao ${ }^{1,3}$, An Guo ${ }^{1}$, Hu Li ${ }^{1}$, Xu Zhang ${ }^{2}$, Jing Han ${ }^{1}$, Shu-sen Wu ${ }^{3}$ \\ 1. Key Lab of Advanced Technologies of Materials (Ministry of Education), School of Materials Science and Engineering, Southwest Jiaotong \\ University, Chengdu 610031, China; \\ 2. School of Mechanics and Engineering, Southwest Jiaotong University, Chengdu 610031, China; \\ 3. State Key Lab of Materials Processing and Die \& Mould Technology, Huazhong University of Science and Technology, Wuhan 430074, China
}

\begin{abstract}
Slurry preparation is one of the most critical steps for semisolid casting, and its primary goal is to prepare slurry with uniformly distributed fine globules. In this work, electromagnetic stirring (EMS) and the addition of Sc and Zr elements were used to prepare semisolid slurry of 7A04 aluminum alloy in a large diameter slurry maker. The effects of different treatments on the microstructure, composition and their radial homogeneity were investigated. The results show that, compared to the slurry without any treatment, large volume slurry with finer and more uniform microstructure can be obtained when treated by EMS, Sc, or $\mathrm{Zr}$ additions individually. EMS is more competent in the microstructural and chemical homogenization of the slurry while Sc and Zr additions are more excellent in its microstructural refinement. The combined treatment of EMS, Sc and $\mathrm{Zr}$ produces premium 7A04 aluminum alloy slurry with uniformly distributed fine $\alpha$-Al globules and composition. The interaction mechanism between EMS and Sc and Zr additions was also discussed.
\end{abstract}

Key words: aluminum alloy; Zr and Sc additions; semisolid slurry; electromagnetic stirring (EMS); homogeneity

CLC numbers: TG146.21 Document code: A Article ID: 1672-6421(2017)03-188-06

Cemisolid casting is a promising manufacturing technique for automobile, aviation and railway vehicle parts ${ }^{[1-3]}$. Semisolid slurry preparation is one of the most critical steps for semisolid casting, and its primary goal is to prepare slurry with uniformly distributed fine globules. Among various methods ${ }^{[4-7]}$ of semisolid slurry preparation, electromagnetic stirring (EMS) is particularly attractive as the stirring intensity can be easily controlled and the melt is free of pollution ${ }^{[8-10]}$. However, the slurry primary phase in a large diameter maker (hereafter referred to as large volume slurry) is hard to be refined and homogenized due to the sharp decrease of electromagnetic force from the

\footnotetext{
*Jun-wen Zhao

Male, born in 1982, Ph.D. and associate professor. His research interests mainly focus on advanced processing of light alloys such as die casting, semisolid metal processing and additive manufacturing; and light metal alloy based functional materials. He has so far published over 30 papers in national and international journals.
}

E-mail: swjtuzjw@swjtu.edu.cn

Received: 2016-10-24; Accepted: 2017-03-20 periphery to the interior ${ }^{[11,12]}$

Scandium $(\mathrm{Sc})$ and zirconium $(\mathrm{Zr})$ are potent grain refiners for $\mathrm{Al}$ alloys ${ }^{[13,14]}$. With the addition of Sc and $\mathrm{Zr}$ elements (hereafter referred to as GR), numerous heterogeneous nuclei can be formed in Al alloy slurry, which also can contribute to the refinement and homogeneity of the slurry microstructure. For these reasons, the compound treatment including EMS, Sc and $\mathrm{Zr}$ additions is supposed to obtain large volume slurry with well dispersed fine primary $\alpha$-Al globules. In this research, the effect of combined treatment of EMS, and $\mathrm{Sc}$ and $\mathrm{Zr}$ additions on the microstructure and the homogenizing of aluminum alloy large volume slurry was investigated.

\section{Experimental procedure}

Figure 1 shows the schematic diagram of the slurry maker used in this study, including EMS induction coils, heat resistance wire, temperature controller and EMS controller. The EMS was generated by the induction coils, for which the intensity and frequency could be 
adjusted by the EMS controller. The graphite crucible put in the slurry maker had an inner diameter of $180 \mathrm{~mm}$, and three thermocouples were placed at the edge $(R)$, middle $(0.5 R)$ and center $(0 \mathrm{R})$ of the crucible to monitor the temperature of the corresponding positions. The temperature and cooling rate of the slurry were controlled by a temperature controller.

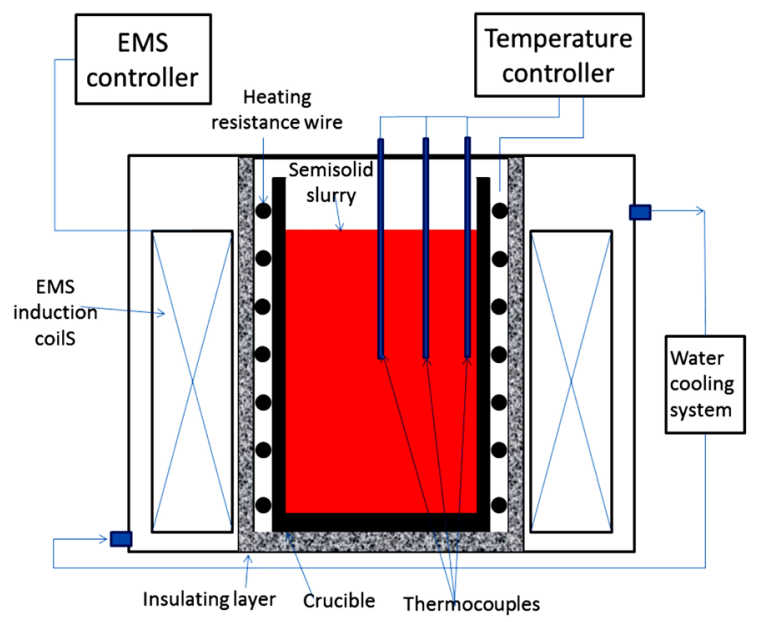

Fig. 1: Schematic diagram of slurry maker used in this study

7A04 (Chinese code) aluminum alloy was used in this study, and its main chemical compositions were $\mathrm{Zn} 6.32 \mathrm{wt} . \%, \mathrm{Mg}$ 1.9wt.\%, $\mathrm{Cu} 1.8$ wt.\% and $\mathrm{Al}$ balance. The solidus and liquidus points of this alloy, determined by DSC, are $478^{\circ} \mathrm{C}$ and $637^{\circ} \mathrm{C}$, respectively. The alloy was melted in a graphite crucible using an electric resistance furnace. For treatment of grain refiner, $0.20 \mathrm{wt} . \% \mathrm{Sc}$ and $0.15 \mathrm{wt} . \% \mathrm{Zr}$ was added into the melt in the form of a master alloy. After being degassed at $750{ }^{\circ} \mathrm{C}$ for 15 min and cooled to $650{ }^{\circ} \mathrm{C}$, about $5 \mathrm{~kg}$ of the melt was poured into the crucible and EMS of $5 \mathrm{~Hz}$ and $3 \mathrm{~kW}$ was applied. As the temperature of the melt reached $631{ }^{\circ} \mathrm{C}$ in $5 \mathrm{~min}$, the slurry was extracted out by a quartz tube with an inner diameter of $6 \mathrm{~mm}$ at the positions of $0 \mathrm{R}, 0.5 \mathrm{R}, \mathrm{R}$ and quenched instantly in water.

The quenched rods were used as samples for metallographic observation. Micrographs of the samples were analyzed using a software program for metallographic quantitative analysis, where the average particles diameter (APD) $D$ and the average shape coefficient (APC) $F$ were used to characterize the size and shape of the primary $\alpha-\mathrm{Al}$ particles and are defined as:

$$
\begin{aligned}
& D=2(A / \pi)^{1 / 2} \\
& F=4 \pi A / P^{2}
\end{aligned}
$$

where, $A$ is the sectional area of a particle in a micrograph, and $P$ is the circumference. The APD and ASC were calculated by the software based on all of the primary particles in a photograph.

The radial homogeneity of the slurry microstructure was evaluated by the variation coefficient $\left(C_{V}\right)$ of the APD, namely

$$
C_{V}=S_{T} / \bar{D}_{T}
$$

where, $S_{T}$ and $\bar{D}_{T}$ are the standard deviation and the average value of APDs at the positions of $0 \mathrm{R}, 0.5 \mathrm{R}$ and $\mathrm{R}$, respectively.

The composition of all the rods was analyzed using an electric spark direct reading spectrometer to determine macro-segregation of the alloying elements. To identify the effect of microscopic homogeneity of alloying elements, the chemical elements at the grains boundaries and inside the grains were analyzed by EDS.

\section{Results}

\subsection{Effect of different treatments on microstructure}

Figure 2 presents the typical microstructures at different positions of the 7A04 aluminum alloy semisolid slurry prepared by different processes, and its statistical results can be seen in Fig. 3. The treatment of GR or EMS has a pronounced influence on the morphologies of the primary $\alpha-\mathrm{Al}$ particles and its homogeneity. For the slurry without any treatment [Fig. 2(a-c)], the coarse primary $\alpha$-Al dendrites were observed at all of the positions in the microstructure. The average particles diameters from the center to the edge were 65 , $75,79 \mu \mathrm{m}$. After individual treatment of EMS [Fig. 2(d-f)] or GR [Fig. 2(g-i)], the microstructure was evidently refined and homogenized. The average particles diameter at all positions was approximately $60 \mu \mathrm{m}$ with EMS treatment, while GR treatment could achieve a finer slurry microstructure with an average particles diameter of $45-50 \mu \mathrm{m}$. For the combined treatment of GR and EMS [Fig. 2(j-1)], the microstructures with an average particles diameter of $36 \mu \mathrm{m}$ were achieved.

Figure 3 (b) indicates that the average shape coefficient, i.e., the roundness of the primary $\alpha$-Al particles was also affected by the treatment methods of the slurry. The average shape coefficient of the primary $\alpha$-Al particles was 0.49 for EMS and 0.63 for GR treatment, both much higher than that without treatment. In the case of the combination of EMS and GR, the average shape coefficient could be further enhanced to 0.68 . However, there was no striking difference between the ASCs at different positions under all processes.

Table 1 shows the variation coefficient $C_{V}$ of the microstructures of the semisolid slurry obtained by four kinds of slurry preparation methods. The high $C_{V}$ value demonstrates a relatively poor radial uniformity for the slurry microstructure without any treatment. The $C_{V}$ value was decreased by $47.7 \%$ with GR treatment and $76 \%$ for EMS treatment. With the combined treatment of GR and EMS, the $C_{V}$ value was decreased to $0.8 \%$, suggesting the combined application could substantially inhibit the inhomogeneity of semisolid slurry.

The above results indicate that for large volume slurry, EMS is favoured to obtain uniform microstructure while $\mathrm{Sc}$ and $\mathrm{Zr}$ can refine the microstructure remarkably. Since the combined treatment incorporates the advantages of both EMS and GR, the slurry microstructure is finer and more uniform than those 

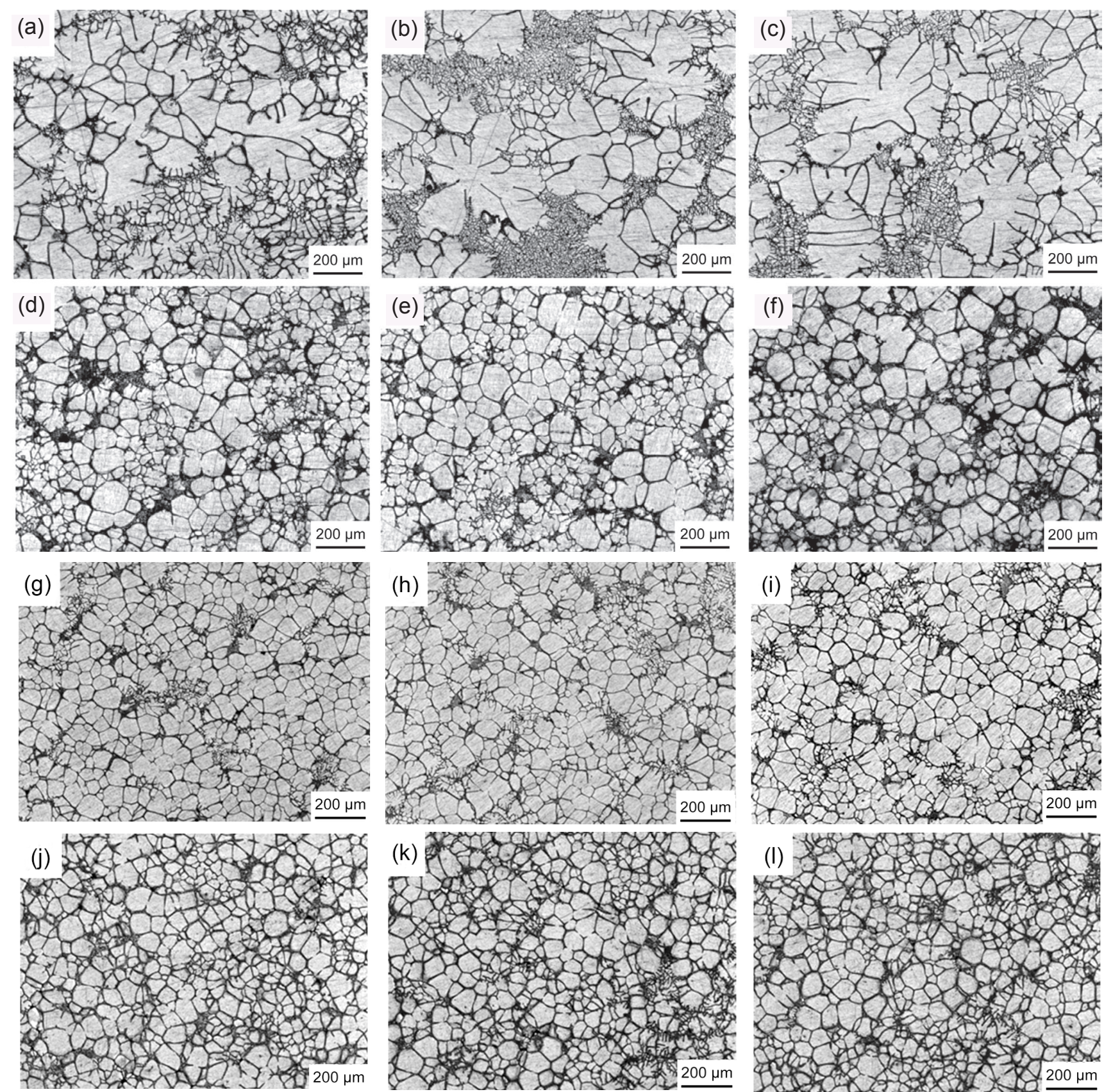

Fig. 2: Microstructure at different positions of $7 \mathrm{A0} 4 \mathrm{Al}$ alloy semisolid slurry prepared by different processes: Without any treatment: (a), (b), (c) for positions of $0 R, 0.5 R$, R, respectively; EMS: (d), (e), (f) for positions of $0 R, 0.5 R, R$, respectively; GR: (g), (h), (i) for positions of $0 R, 0.5 R$, R, respectively; EMS and GR: (j), k), (I) for positions of $0 R, 0.5 R$, $R$, respectively.
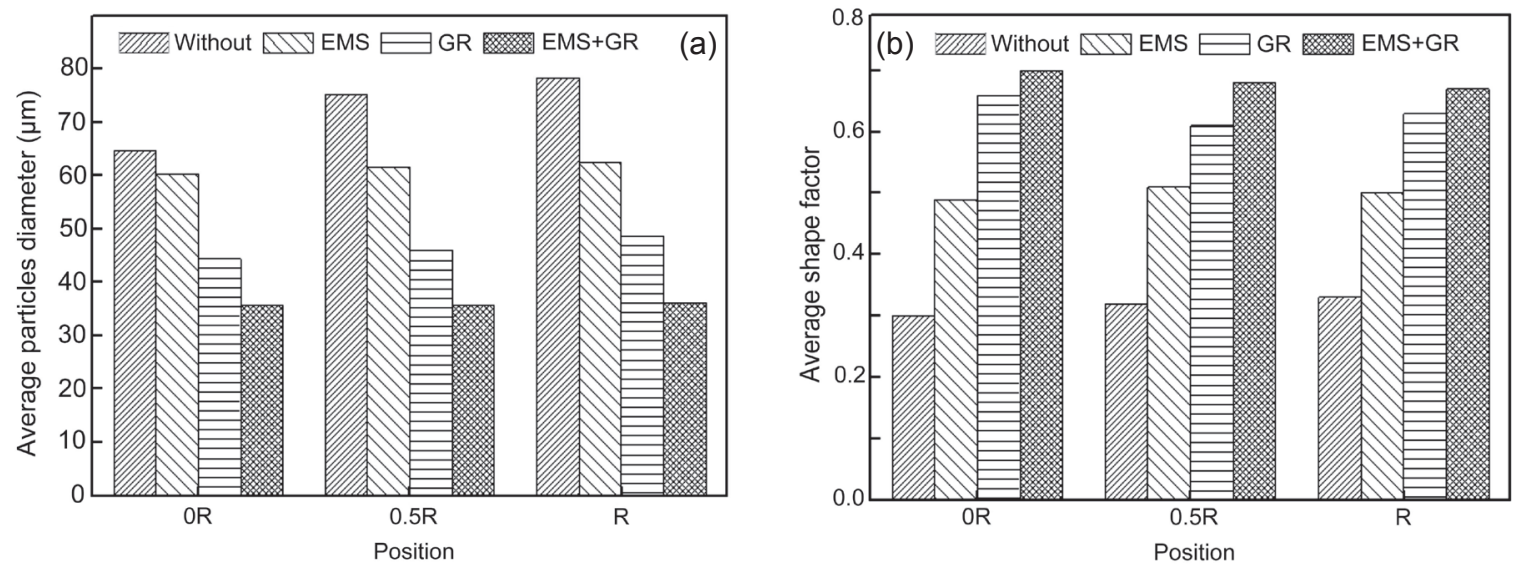

Fig. 3: Statistical results for average particles diameter (a) and average shape factor (b) of microstructures of 7A04 Al alloy semisolid slurry prepared by different processes 
Table 1: Variation coefficient of microstructures of 7A04 aluminum alloy semisolid slurry prepared by different processes

\begin{tabular}{|ccccc}
\hline Process & Without any treatment & EMS & GR & EMS+GR \\
\hline Variation coefficient $(\%)$ & 8.78 & 2.09 & 4.59 & 0.78
\end{tabular}

prepared by other processes.

\subsection{Effect of different treatments on composition variation}

As illustrated in Fig. 4, for the main alloying elements $\mathrm{Zn}, \mathrm{Mg}$ and $\mathrm{Cu}$, the concentration means are very similar under different processes, whereas the ranges are distinct between processes with and without EMS. For the conventional slurry, the ranges of the three elements are all above $0.1 \%$. In contrast, with the application of EMS, the ranges of the alloying elements, esp., $\mathrm{Mg}$ and $\mathrm{Zn}$, diminish significantly, suggesting the solute distribution becomes more uniform. However, the segregation of these elements could not be considerably moderated with the single treatment of GR. Furthermore, compared with the sole treatment of EMS, the uniformity of $\mathrm{Zn}, \mathrm{Mg}$ and $\mathrm{Cu}$ distribution could not be further improved with the combined treatment of EMS and GR.

As shown in Table 2, all the detected elements were largely enriched at the grain boundaries for the conventional slurry: the concentration of $\mathrm{Cu}$ at the grain boundaries even reached over $10 \%$, dozens of times higher than that inside the grains. In comparison, the segregation of alloying elements was greatly reduced after processing with EMS, and $\mathrm{Cu}$ concentration at the boundaries decreased to $4.52 \%$, just less than half of that without EMS. Moreover, the addition of GR can also alleviate the segregation, but is less significant than the former. With EMS, the GR elements, i.e., Sc, Zr, are also homogenized, while the distribution of the main alloying elements didn't change too much, with the combined application of EMS and GR, just similar to that with the single application of EMS.
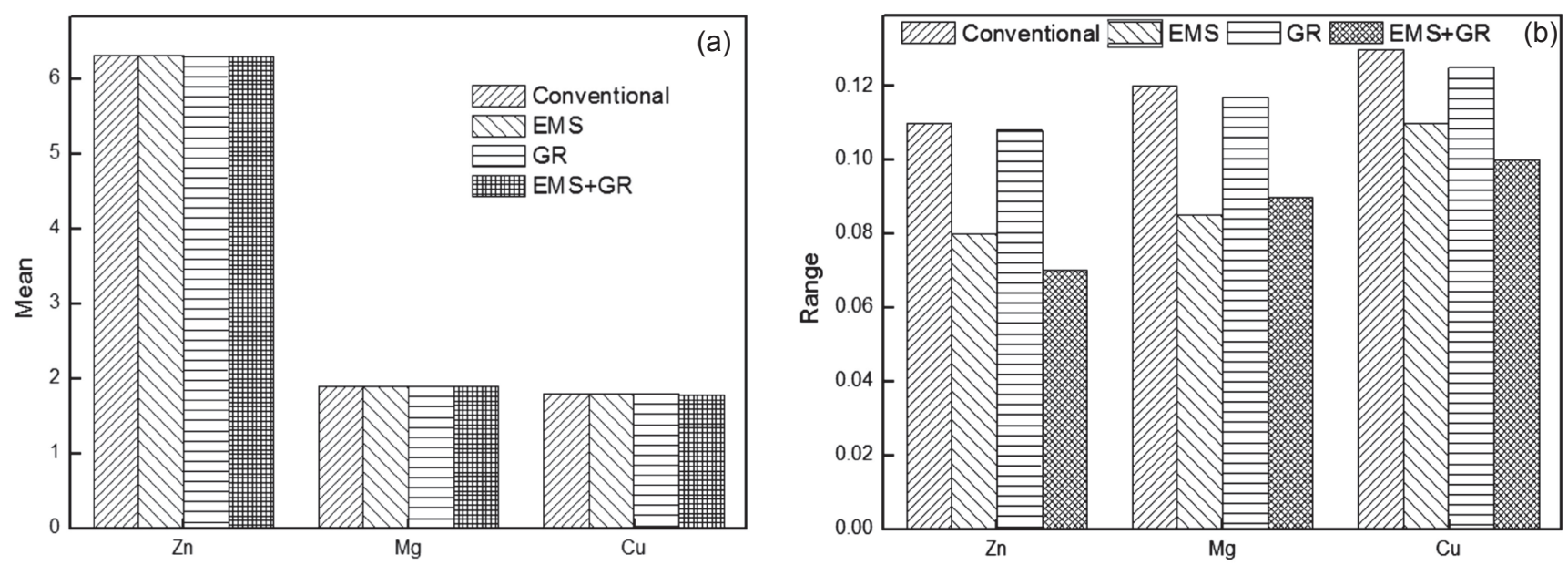

Fig. 4: Statistic results for concentration mean (a) and range (b) of main alloying elements by different processes

Table 2: Typical chemical composition (\%) at grain boundaries and inside grains for samples prepared by different processes

\begin{tabular}{|c|c|c|c|c|c|c|c|}
\hline Process & Position & Zn & Mg & $\mathrm{Cu}$ & $\mathrm{Zr}$ & Sc & Al \\
\hline \multirow{2}{*}{ Conventional } & A & 4.34 & 1.16 & 0.22 & - & - & \multirow{8}{*}{ Balance } \\
\hline & B & 9.82 & 3.8 & 10.25 & - & - & \\
\hline \multirow{2}{*}{ EMS } & C & 5.8 & 1.62 & 1.31 & - & - & \\
\hline & D & 8.16 & 3 & 4.52 & - & - & \\
\hline \multirow{2}{*}{ GR } & E & 4.84 & 0.66 & 0.54 & 0.11 & 0.05 & \\
\hline & $F$ & 9.76 & 1.94 & 6.1 & 0.47 & 0.4 & \\
\hline \multirow{2}{*}{ EMS+GR } & G & 5.61 & 1.7 & 1.18 & 0.13 & 0.11 & \\
\hline & $\mathrm{H}$ & 9.85 & 2.54 & 4.2 & 0.17 & 0.27 & \\
\hline
\end{tabular}

Note: $\mathrm{A}, \mathrm{C}, \mathrm{E}$ and $\mathrm{G}$ refer to the detected positions inside the grains; $\mathrm{B}, \mathrm{D}, \mathrm{F}$ and $\mathrm{H}$ refer to detected positions at the grain boundaries. 


\section{Discussion}

The measured cooling curves of 7A04 aluminum alloy semisolid slurry without and with EMS are shown in Fig. 5. For the conventional slurry, the temperature difference is distinct at the edge, middle and center though their cooling rates are similar. The temperature at the region closer to the center is higher, with a $2-3{ }^{\circ} \mathrm{C}$ difference between the two adjacent measured positions. On the contrary, there is no notable temperature difference at the three positions when EMS is applied. Therefore, the chemical inhomogeneity of the slurry without any treatment is mainly derived from the uneven temperature field of slurry from the edge to the center in the crucible. When EMS is applied, a forced convection is introduced into the slurry. As shown in Fig. 5 and evidenced by other researchers ${ }^{[15,16]}$, the convection helps to homogenize the temperature field and the solute field, facilitating the uniform dispersion of nuclei into

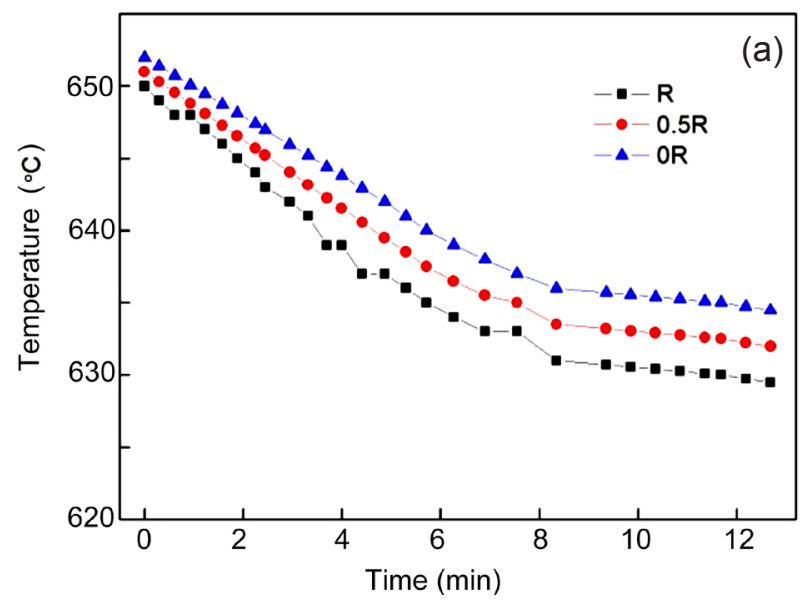

various parts of the crucible as well as equiaxed growth in the whole melt, thus the slurry uniformity can be greatly improved. Furthermore, the convection assists the dendrites fragmentation and abscission of wall crystal during solidification, contributing to the refinement of the microstructure.

On the other hand, with the addition of $\mathrm{Zr}$ and $\mathrm{Sc}$ into the $\mathrm{Al}$ alloy melt, large quantities of $\mathrm{Al}_{3}(\mathrm{Zr}, \mathrm{Sc})$ particles are generated throughout the melt ${ }^{[17]}$. $\mathrm{As}^{\mathrm{Al}_{3}}(\mathrm{Zr}, \mathrm{Sc})$ particles are excellent heterogeneous nucleants for $\mathrm{Al}$, primary $\alpha-\mathrm{Al}$ grains are formed on these effective nucleation sites, leading to much finer slurry microstructure over EMS ${ }^{[18]}$. Nonetheless, the addition of Sc and $\mathrm{Zr}$ has little effects on the temperature variation between different positions in the crucible with large diameter, accounting for the higher value of variation coefficient.

With the action of EMS, agglomeration and segregation of $\mathrm{Al}_{3}(\mathrm{Zr}, \mathrm{Sc})$ particles are eliminated throughout the melt, resulting in more effective nucleation sites being available for

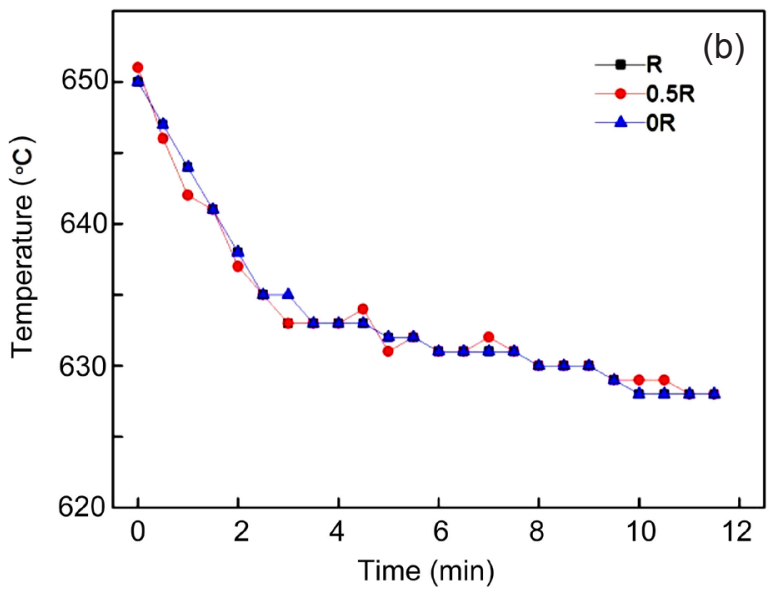

Fig. 5: Measured cooling curves of 7A04 aluminum alloy semisolid slurry: (a) without EMS; (b) with EMS

Al. Moreover, EMS induced flow produces uniform solute and thermal field, inhibiting the dendritic growth of $\alpha-\mathrm{Al}$ grains. Consequently, slurry with finer, more globular and more uniform primary $\alpha-\mathrm{Al}$ grains can be achieved under combined action of GR and EMS.

For the distribution of the alloying elements throughout the slurry, because GR has little effect on the macroscopic convection of slurry, hence the macro-segregation could not be eliminated. Microscopically, as more grain boundaries are available due to grain refinement, that is, more places for distribution of alloying elements, and consequently their content at the single boundary is decreased. Furthermore, with nuclei provided by GR, the melt will start to solidify at a higher temperature, which promotes a higher solution of alloying elements inside grains. As a result, the micro-segregation between grains and boundaries is reduced with the addition of GR.

\section{Conclusion}

Large volume slurry of 7A04 aluminum alloy with fine and uniform microstructure can be obtained when treated by EMS, Sc or $\mathrm{Zr}$ additions individually. However, EMS is more favorable to obtain slurry with uniform microstructure and composition, while Sc or $\mathrm{Zr}$ can remarkably refine the slurry microstructure. The combined treatment of EMS, Sc and $\mathrm{Zr}$ can obtain large volume semisolid slurry with uniformly distributed finer primary $\alpha$-Al globules. 7A04 aluminum alloy slurry with average particles diameter of $36 \mu \mathrm{m}$, shape coefficient of 0.68 and variation coefficient of $0.8 \%$ can be achieved.

\section{References}

[1] Atkinson $\mathrm{H} \mathrm{V}$. Modelling the semisolid processing of metallic alloys. Progress in Materials Science, 2005, 50(3): 341-412.

[2] Fan Z. Semisolid metal processing. International Materials Reviews, 2002, 47(2): 49-85.

[3] Tan Yanlong, Fu Xinsheng, Wang Dansan, et al. Study of defects and improve technics on semi-solid rheologic squeeze casting of gear of tachometer. Foundry, 2010, 59(10):10491052. (In Chinese)

[4] Li Yanlei, Li Yuandong, Li Chun, et al. Microstructure characteristics and solidification behavior of wrought aluminum 
alloy 2024 rheo-diecast with self-inoculation method. China Foundry, 2012, 9(4): 328-336.

[5] Gencalp S and Saklakoglu N. Semisolid Microstructure Evolution during Cooling Slope Casting under Vibration of A380 Aluminum Alloy. Materials and Manufacturing Processes, 2010, 25(9): 943-947.

[6] Yang B, Mao W, and Song X. Microstructure characteristics and mechanical properties of rheocasting 7075 aluminum alloy. China Foundry, 2013, 10(5): 277-281.

[7] Xu Chao, Zhao Junwen, Luo Qinglai, et al. Effects of Al-5Ti1B Grain Refiner on Solidification Microstructure of 7A04 Aluminum Alloy. Rare Metal Science and Engineering, 2016 (6): 1559-1564. (In Chinese)

[8] Mapelli C, Gruttadauria A, and Peroni M. Application of electromagnetic stirring for the homogenization of aluminium billet cast in a semi-continuous machine. Journal of Materials Processing Technology, 2010, 210(2): 306-314.

[9] Kang C G and Lee S M. The effect of solid fraction and indirect forging pressure on mechanical properties of wrought aluminum alloy fabricated by electromagnetic stirring. The International Journal of Advanced Manufacturing Technology, 2009, 42(1-2): 73-82.

[10] Charles V. Elaboration of semisolid alloys by means of new electromagnetic rheocasting processes. Metallurgical Transactions B, 1992, 23(2): 189-206.

[11] Zhang Haitao, Nagaumi H, Zuo Yubo, et al. Coupled modeling of electromagnetic field, fluid flow, heat transfer and solidification during low frequency electromagnetic casting of
7XXX aluminum alloys: Part 1: Development of a mathematical model and comparison with experimental results. Materials Science and Engineering: A, 2007, 448(1): 189-203.

[12] Zhu Yanli, Zhao Junwen, Li Wei, et al. Effect of electromagnetic stirring on microstructure of large-volume semi-solid slurry of 7A04 aluminum alloy. The Chinese Journal of Nonferrous Metals, 2014, 24(11): 2735-2742. (In Chinese)

[13] Huskins E L, Cao B, and Ramesh K T. Strengthening mechanisms in an Al-Mg alloy. Materials Science and Engineering: A, 2010, 527(6): 1292-1298.

[14] Kilicaslan M, Lee W, Lee T, et al. Effect of Sc addition on the microstructure and mechanical properties of as-atomized and extruded Al-20Si alloys. Materials Letter, 2012, 71: 164-167.

[15] Eckert S, Nikrityuk P A, Willers B, et al. Electromagnetic melt flow control during solidification of metallic alloys. The European Physical Journal Special Topics, 2013, 220(1): 123137.

[16] Barman N and Dutta P. Effect of process parameters on transport phenomena during solidification in the presence of electromagnetic stirring. Transactions of the Indian Institute of Metals, 2009, 62(4-5): 469-474.

[17] Milman Y V, Sirko A I, and Lotsko D V. Microstructure and mechanical properties of cast and wrought Al-Zn-Mg-Cu alloys modified with Zr and Sc. Materials Science Forum, 2002, 396402.

[18] Senkov O N, Senkova S V, and Shagiev M R. Effect of Sc on aging kinetics in a direct chill cast Al-Zn-Mg-Cu Alloy. Metallurgical and Materials Transactions A, 2008, 39(5): 1034-1053.

This work was financially supported by the National Key Technology R\&D Program (2015BAG12B01), the National Natural Science Foundation of China (11672251) and the State Key Lab of Materials Processing and Die \& Mould Technology, Huazhong University of Science and Technology (P2015-10). 